\title{
Removal of a Trigger Cord Stuck between Bands during Endoscopic Multiple-Band Ligation for Treating Esophageal Variceal Hemorrhage
}

\author{
Nam Seok Ham, Danbi Lee, Sung Hyun Won, Jeongseok Kim, Seokjung Jo, Sangyoung Yi and Seol So \\ Department of Gastroenterology, University of Ulsan College of Medicine, Asan Medical Center, Seoul, Korea
}

Endoscopic variceal ligation is the preferred endoscopic treatment method for esophageal variceal bleeding. The incidence of complications such as chest pain, bleeding, stricture formation, and aspiration pneumonia is low. We report a case wherein a malfunctioning multiple-band ligator could have potentially caused damage to the esophageal varices and massive bleeding. The equipment was safely removed using scissors and forceps. To the best of our knowledge, this is the first published report detailing the management of a case of esophageal variceal bleeding. Clin Endosc 2020;53:230-231

Key Words: Complication; Endoscopic variceal ligation; Esophageal varix

\section{INTRODUCTION}

Endoscopic variceal ligation (EVL) is the preferred endoscopic treatment method for esophageal variceal bleeding and is associated with increased survival and minimized rebleeding and complication rates. ${ }^{1,2}$ Potential complications include chest pain, bleeding, stricture formation, aspiration pneumonia, dysphagia, and perforation. The incidence of these complications, however, is low. ${ }^{3}$

\section{CASE REPORT}

A 46-year-old man with liver cirrhosis due to chronic hepatitis B was admitted to our center after an episode of melena occurring 7 hours prior. At the time of admission, his vital signs were normal and stable. He had a history of EVL for

Received: April 2, 2019 Revised: April 30, 2019

Accepted: May 1, 2019

Correspondence: Danbi Lee

Department of Gastroenterology, University of Ulsan College of Medicine, Asan Medical Center, 88 Olympic-ro 43-gil, Sonpa-gu, Seoul 05505, Korea

Tel: +82-2-3010-3907, Fax: +82-2-476-0824, E-mail: leighdb@hanmail.net ORCID: https://orcid.org/0000-0002-8336-0006

(c) This is an Open Access article distributed under the terms of the Creative Commons Attribution Non-Commercial License (http://creativecommons.org/ licenses/by-nc/3.0) which permits unrestricted non-commercial use, distribution, and reproduction in any medium, provided the original work is properly cited. esophageal variceal bleeding 1 year previously. The results of the complete blood count and serum biochemical test were as follows: white blood cells, 4,700/ $\mu \mathrm{L}$; hemoglobin, $9.9 \mathrm{~g} / \mathrm{dL}$; hematocrit, $31.0 \%$; platelets, $118,000 / \mu \mathrm{L}$; prothrombin time, 1.47 international normalized ratio; activated partial thromboplastin time, $40.7 \mathrm{sec}$; aspartate aminotransferase, $24 \mathrm{IU} / \mathrm{L}$; alanine aminotransferase, $21 \mathrm{IU} / \mathrm{L}$; albumin, $3.6 \mathrm{~g} / \mathrm{dL}$; and total bilirubin, $2.4 \mathrm{mg} / \mathrm{dL}$. Endoscopic band ligation (6 Shooter Saeed Multi-Band Ligator; Cook Medical, Bloomington, IN, USA) was performed without sedation. During additional band ligation, the trigger cord malfunctioned and was inserted between the bands on a single varix (Supplementary video 1). The trigger cord was stuck between several bands, and the endoscope could not be retrieved. Forcibly moving the endoscope would have meant tearing the varix and potentially causing massive bleeding. Thus, we had to think of another way to solve the problem immediately. After cutting the trigger cord with scissors (it was connected to the ligator handle) (Fig. 1), we pushed the cord out of the endoscope inside the accessory channel using forceps. After selectively grasping the trigger cord between the bands (Fig. 2), we gradually advanced the endoscope and forceps to pull out the trigger cord between the bands (Fig. 3). After the trigger cord was removed from between the bands, the endoscope was released and retrieved. One month after the procedure, the patient did not experience any hemorrhagic events and received an addi- 


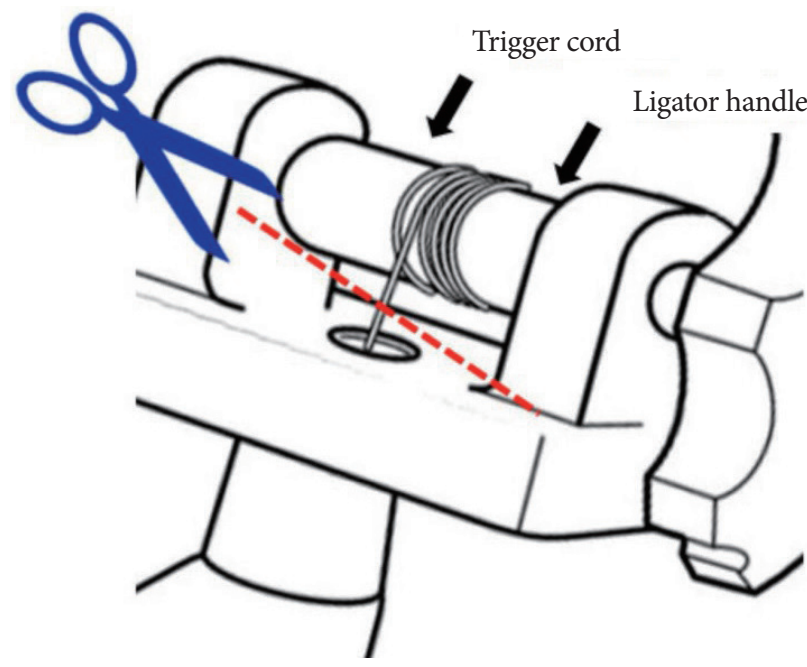

Fig. 1. Cutting the trigger cord connected to the ligator handle with scissors.

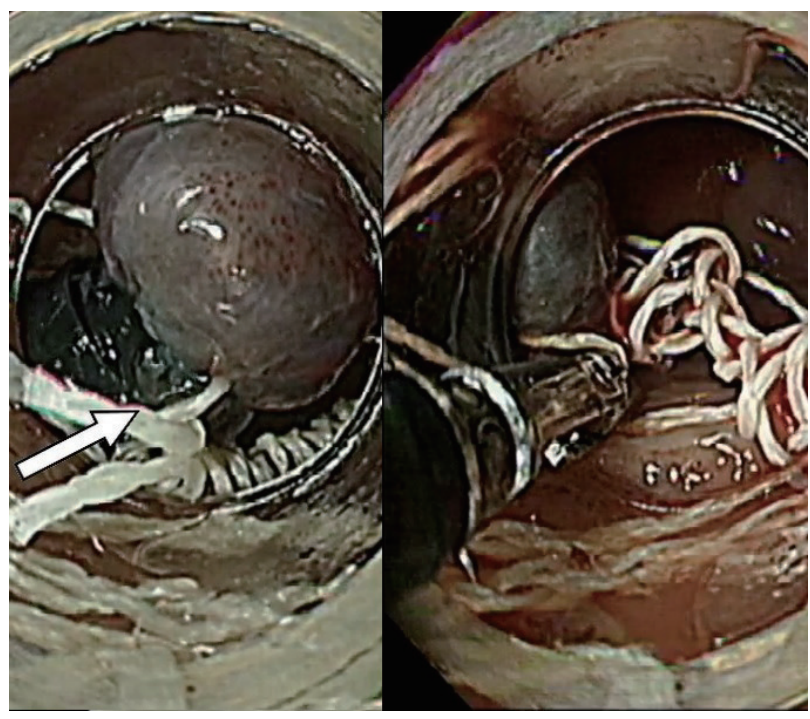

Fig. 2. Selectively grasping the trigger cord from between the bands.

tional EVL procedure.

\section{DISCUSSION}

Our case has been reviewed and investigated by the device manufacturer. They collected all the other ligators that were in stock at that time and experimented to determine if the same event would occur again. However, all the other products

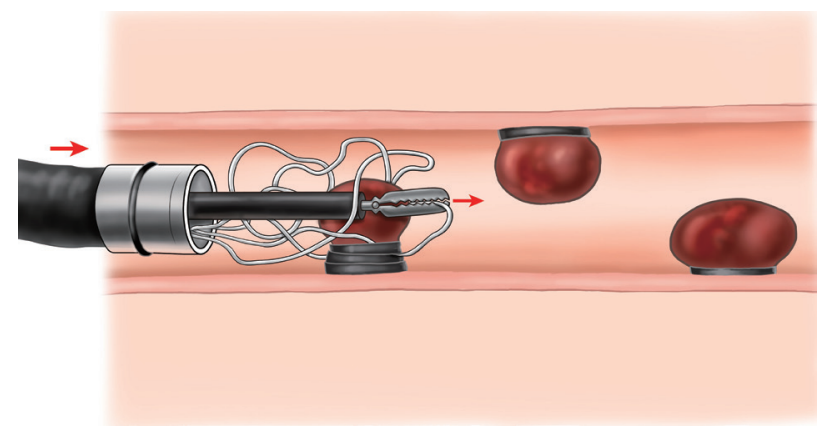

Fig. 3. Gradual advancing of the endoscope and forceps to pull out the trigger cord from between the bands.

worked normally.

In conclusion, the definitive cause of the incident could not be determined through the evaluation of the recalled products or provided video. We set up the device appropriately. The trigger cord on the device appeared to be in the correct position between each band, and the deployment beads were positioned correctly on the device. Therefore, we concluded that this was a rare event that occurred by chance. To our knowledge, this is the first reported case wherein a malfunctioning multiple-band ligator could have led to a potentially serious damage to the esophageal varix, with the risk of massive bleeding. We safely removed the equipment using scissors and forceps.

\section{Conflicts of Interest}

The authors have no financial conflicts of interest.

\section{Supplementary Material}

Video 1 . Inserting a trigger cord between bands during band ligation and successful removal using scissors and forceps (https://doi.org/10.5946/ ce.2019.076.v001).

\section{REFERENCES}

1. Garcia-Tsao G, Sanyal AJ, Grace ND, Carey W. Prevention and management of gastroesophageal varices and variceal hemorrhage in cirrhosis. Hepatology 2007;46:922-938.

2. Hwang JH, Shergill AK, Acosta RD, et al. The role of endoscopy in the management of variceal hemorrhage. Gastrointest Endosc 2014;80:221227.

3. Schmitz RJ, Sharma P, Badr AS, Qamar MT, Weston AP. Incidence and management of esophageal stricture formation, ulcer bleeding, perforation, and massive hematoma formation from sclerotherapy versus band ligation. Am J Gastroenterol 2001;96:437-441. 